\title{
Stability of Fatigued Dislocation Wall Structure in Coarse-Grained and Ultrafine-Grained Aluminum against Monotonic Tensile Deformation
}

\author{
Yukito Nakanishi ${ }^{1, *}$, Yoji Miyajima ${ }^{1}$, Toshiyuki Fujii ${ }^{2}$, Susumu Onaka ${ }^{1}$ and Masaharu Kato ${ }^{1}$ \\ ${ }^{1}$ Department of Materials Science and Engineering, Tokyo Institute of Technology, Yokohama 226-8502, Japan \\ ${ }^{2}$ Department of Innovative and Engineered Materials, Tokyo Institute of Technology, Yokohama 226-8502, Japan
}

Coarse-grained (CG) and ultrafine-grained (UFG) pure aluminum samples fabricated by equal channel angular pressing (ECAP) were cyclically deformed at $77 \mathrm{~K}$ under constant plastic strain amplitude. Monotonic tensile tests were performed at 300 and $77 \mathrm{~K}$ soon after the fatigue tests. In spite of the increase in the tensile strength of fatigued CG Al, tensile ductility decreased remarkably in comparison to that of as-annealed CG Al. On the other hand, the ultimate tensile strength (UTS) and tensile ductility of UFG Al were much higher at $77 \mathrm{~K}$ than those at $300 \mathrm{~K}$. Furthermore, UFG Al at $77 \mathrm{~K}$ maintained high UTS and high tensile ductility even after fatigue tests. Microstructural observation has revealed that dislocation wall structure formed in fatigued CG Al persists after the monotonic tensile tests. However, dislocation wall structure formed in fatigued UFG Al disappeared during early stages of monotonic tensile tests at both 300 and $77 \mathrm{~K}$. These results indicate that the dislocation wall structure in UFG Al is unstable against succeeding monotonic tensile deformation. [doi:10.2320/matertrans.M2012280]

(Received August 16, 2012; Accepted October 19, 2012; Published November 30, 2012)

Keywords: ultra-fine-grained aluminum, equal channel angular pressing, fatigue, tensile deformation, dislocation wall structure, microstructural stability

\section{Introduction}

Ultrafine-grained (UFG) metals have been produced by severe plastic deformation (SPD) such as equal channel angular pressing (ECAP), ${ }^{1)}$ accumulative roll-bonding $(\mathrm{ARB})^{2)}$ and high-pressure torsion (HPT). ${ }^{3)}$ UFG fcc metals are known to show some characteristic physical and mechanical properties that are different from those of coarse-grained (CG) fcc metals, such as easier recrystallization and recovery, ${ }^{4-6)}$ higher temperature and strain-rate dependencies of strength ${ }^{7,8)}$ and deviation from the HallPetch relationship. ${ }^{9,10)}$ In order to reveal the mechanism of such characteristic properties, many researchers have proposed various deformation models of UFG materials. ${ }^{11-27)}$

Fatigue behavior of UFG metals is also unique and different from that of single-crystalline and CG metals. For high-cycle stress-controlled tests where strength is a major factor in determining the fatigue life, UFG metals show superior fatigue life compared with single-crystalline and $C G$ metals. ${ }^{28-31)}$ On the other hand, UFG metals show deteriorated fatigue life for low-cycle strain-controlled fatigue tests where fatigue life is mainly controlled by ductility. ${ }^{28-31)}$ For the low-cycle tests, it is also known that UFG pure aluminum shows hardening followed by softening ${ }^{28,29)}$ and distinct fatigue dislocation structure has not been observed in grains at room temperature. ${ }^{28)}$ In contrast, single-crystalline and CG Al show initial hardening, softening and secondary hardening ${ }^{32-34)}$ with the formation of characteristic dislocation structure such as vein, ${ }^{35,36)}$ wall, ${ }^{35,36)}$ labyrinth $^{32,35,37)}$ and cell ${ }^{28,34)}$ structures.

Although the cyclic deformation behavior of UFG Al is worth investigating more in detail, most reports were on commercially pure $\mathrm{Al}$ or on $\mathrm{Al}$ alloys. We have recently reported that test temperature plays an important role on the fatigue behavior of high purity UFG $\mathrm{Al}$ and very fine

*Corresponding author, E-mail: nakanishi.y.ac@m.titech.ac.jp dislocation wall structure is formed when tested at $83 \mathrm{~K}$ in grains smaller than a few micrometers. ${ }^{38,39)}$

In this study, low-cycle fatigue tests were carried out under plastic-strain control at $77 \mathrm{~K}$ using $\mathrm{CG}$ and UFG $\mathrm{Al}$, and monotonic tensile tests were performed in succession either at 300 or $77 \mathrm{~K}$ after the fatigue tests. From the results of monotonic tensile tests and transmission electron microscopy (TEM), the formation and stability of the fatigued dislocation structure are studied.

\section{Experimental Procedure}

High-purity Al (99.98 mass\%) was used for the present study. Al sheets were annealed at $673 \mathrm{~K}$ for $2 \mathrm{~h}$ to obtain a fully recrystallized material. Average grain size of the asannealed Al was about $300 \mu \mathrm{m}$ and this material will be referred to as as-annealed $\mathrm{CG} \mathrm{Al}$.

CG Al samples cut into a rod shape of $10 \mathrm{~mm}$ in diameter and $60 \mathrm{~mm}$ in length were prepared for the ECAP deformation at $300 \mathrm{~K}$. Each rod was subjected to 8 passes of ECAP under route $\mathrm{B}_{\mathrm{c}}$ (rotation by $90^{\circ}$ in each pass). ${ }^{1 \text { ) }}$ After the ECAP deformation, average grain size of UFG Al became about $1.3 \mu \mathrm{m}$ and this material will be referred to as as-ECAPed UFG Al. According to Salem et al., ${ }^{40)}$ grain refinement in pure $\mathrm{Al}$ is strongly dependent on the purity of the material. In fact, Kawasaki et al. has reported that the grain size of 99.99 mass \% Al can be at the smallest $1.2 \mu \mathrm{m}$ by the ECAP technique. ${ }^{41)}$ Therefore, the obtained average grain size of $1.3 \mu \mathrm{m}$ in the present study is reasonably larger than that of commercially pure Al fabricated by the same ECAP condition. ${ }^{28,29)}$ Nevertheless, we have chosen high purity $\mathrm{Al}$ for the purpose of avoiding the effects of impurities and investigating the primary mechanical and physical properties of Al.

The fatigue specimens with the gauge length of $10 \mathrm{~mm}$ and cross-sectional area of $5 \times 6 \mathrm{~mm}^{2}$ were taken from the central part of the as-ECAPed rods by spark erosion in the direction 
parallel to the rod axis. The specimens were mechanically polished with silicon-carbide paper and electrolytically polished using solution of $20 \%$ perchloric acid and $80 \%$ methanol.

Fully reversed tension-compression low-cycle fatigue tests were carried out at $77 \mathrm{~K}$ for these CG (as-annealed) and UFG (as-ECAPed) Al specimens under a constant plastic strain amplitude of either $\varepsilon_{\mathrm{pl}}=1 \times 10^{-3}$ or $5 \times 10^{-3}$ using an electro-hydraulic testing machine (Shimadzu Servopet). The specimens were immersed in liquid nitrogen to achieve the low temperature atmosphere during the fatigue tests. Strain was measured with an extensometer mounted directly on the gauge section and constant strain rate of $4 \times 10^{-3} \mathrm{~s}^{-1}$ was employed using a triangular command signal. After reaching the saturation of stress amplitude, fatigue tests were stopped at the cumulative plastic strain $\varepsilon_{\text {cum }}$ of 10 (for UFG Al) and 50 (for $\mathrm{CG} \mathrm{Al}$ ). Here, the cumulative plastic strain is defined as

$$
\varepsilon_{\mathrm{cum}}=4 N \varepsilon_{\mathrm{pl}}
$$

where $N$ is the number of fatigue cycles. Since UFG Al generally shows shorter fatigue life than $\mathrm{CG} \mathrm{Al}$ at low-cycle fatigue tests, ${ }^{28,29,31)}$ it is reasonable that UFG $\mathrm{Al}$ reached stress saturation at smaller cumulative plastic strain than $C G$ Al. No cracks were observed on the surface of specimens after the fatigue tests mentioned above.

The tensile specimens with a gauge length of $10 \mathrm{~mm}$ and cross-sectional area of $1 \times 3 \mathrm{~mm}^{2}$ were sliced from the fatigue specimens and polished under the same conditions as those used to prepare fatigue specimens. Monotonic tensile tests were carried out at 300 and $77 \mathrm{~K}$ for un-fatigued (asannealed and as-ECAPed) and fatigued specimens at a constant strain rate of $4 \times 10^{-3} \mathrm{~s}^{-1}$ using an Instron-type testing machine (Minebea TG-50kN).

The fatigued and monotonically deformed specimens were sliced into $3 \mathrm{~mm}$ diameter disks and ground down to a thickness of $0.2 \mathrm{~mm}$ with silicon-carbide paper. Then, the samples were electrolytically polished on a twin-jet polisher (Struers Tenupol-5) in solution of 8\% perchloric acid, 10\% 2-butoxyethanol and $82 \%$ methanol. TEM observations were performed by using a JEOL 2011 microscope with an acceleration voltage of $200 \mathrm{kV}$.

During the course of this study, we found that when fatigued specimens at $77 \mathrm{~K}$ were stored at room temperature, dislocation structure formed by the fatigue test disappeared in a few months for CG $\mathrm{Al}$ and in a few weeks for UFG Al. To avoid such possibility of natural annealing and to ensure the preservation of dislocation structure until TEM observation, fatigued and deformed specimens were always stored in liquid nitrogen.

More concretely, specimens were handled very carefully so that they were exposed at room temperature for less than $1 \mathrm{~h}$ between the fatigue and tensile tests and between the tensile tests and the TEM observation.

\section{Results}

\subsection{Fatigue behavior of CG and UFG Al}

Figure 1 shows cyclic hardening curves of CG (asannealed) and UFG (as-ECAPed) Al fatigued at $77 \mathrm{~K}$. CG

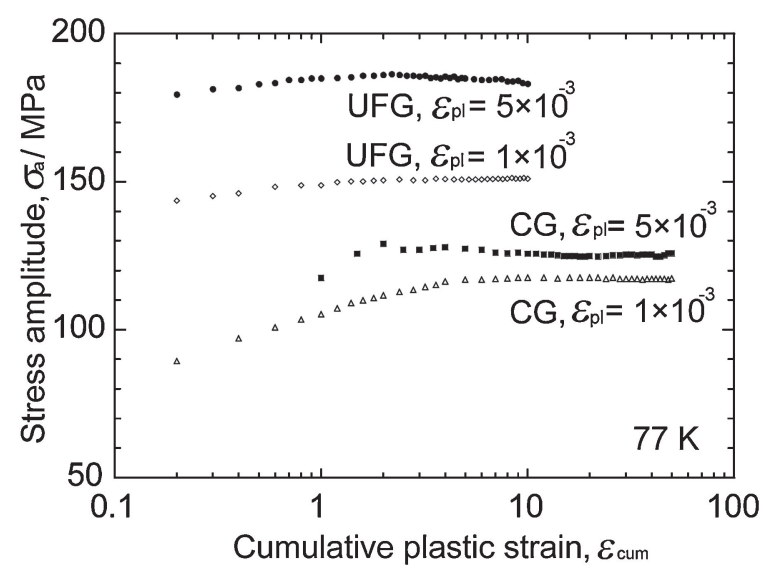

Fig. 1 Cyclic hardening curves of CG and UFG Al fatigued under constant plastic strain amplitudes $\varepsilon_{\mathrm{pl}}=1 \times 10^{-3}$ and $5 \times 10^{-3}$ at $77 \mathrm{~K}$

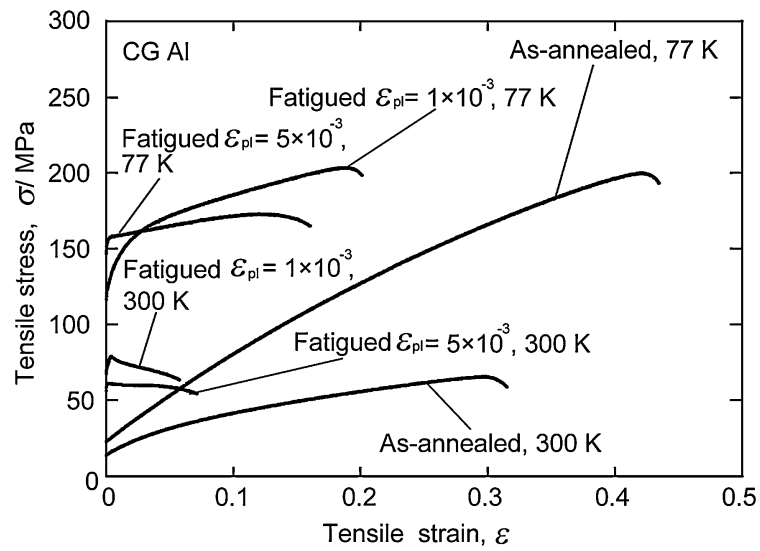

Fig. 2 Stress-strain curves at 300 and $77 \mathrm{~K}$ of as-annealed and fatigued CG Al.

Al shows rapid hardening to saturation. At this test temperature, $\mathrm{CG} \mathrm{Al}$ does not show either softening or secondary hardening characteristic of the room-temperature fatigue behavior of single-crystalline and CG $\mathrm{Al}^{31-33)}$ The saturation stress of CG Al in this study was $118 \mathrm{MPa}\left(\varepsilon_{\mathrm{pl}}=1 \times 10^{-3}\right)$ and $126 \mathrm{MPa}\left(\varepsilon_{\mathrm{pl}}=5 \times 10^{-3}\right)$.

The fatigue behavior of UFG $\mathrm{Al}$ at $77 \mathrm{~K}$ is similar to that of $\mathrm{CG} \mathrm{Al}$ at $77 \mathrm{~K}$. UFG $\mathrm{Al}$ shows slight hardening followed by stress saturation. The saturation stress of UFG $\mathrm{Al}$ in this study was $151 \mathrm{MPa}\left(\varepsilon_{\mathrm{pl}}=1 \times 10^{-3}\right)$ and $186 \mathrm{MPa}\left(\varepsilon_{\mathrm{pl}}=\right.$ $\left.5 \times 10^{-3}\right)$. Since UFG Al has experienced extensive work hardening during the ECAP deformation, it is natural that cyclic hardening rate of UFG Al is lower compare to that of CG Al.

\subsection{Monotonic tensile deformation behavior of fatigued Al}

The tensile stress-strain curves at 300 and $77 \mathrm{~K}$ of asannealed and fatigued $\mathrm{CG} \mathrm{Al}$ are shown in Fig. 2. For both as-annealed and fatigued $\mathrm{CG} \mathrm{Al}$, the ultimate tensile strength (UTS) and tensile ductility are larger at $77 \mathrm{~K}$ than at $300 \mathrm{~K}$. When test temperature is the same, fatigued CG Al shows much higher yield strength and much lower tensile ductility than as-annealed CG Al. 


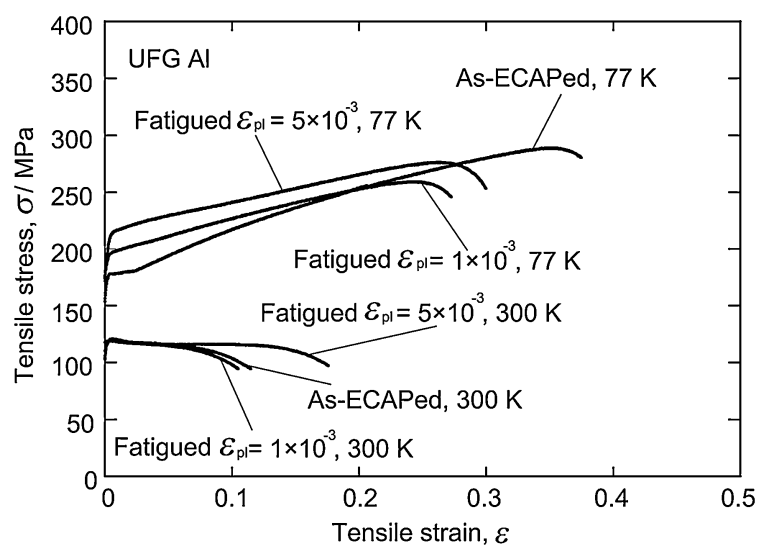

Fig. 3 Stress-strain curves at 300 and $77 \mathrm{~K}$ of as-ECAPed and fatigued UFG Al.

The monotonic tensile deformation behavior of UFG Al was quite different from that of $\mathrm{CG}$ Al. Figure 3 shows the tensile stress-strain curves of as-ECAPed and fatigued UFG $\mathrm{Al}$ monotonically deformed at 300 and $77 \mathrm{~K}$. There are at least two remarkable points to be noted in Fig. 3. First, regardless of as-ECAPed or fatigued UFG Al, UTS and tensile ductility at $77 \mathrm{~K}$ are much higher than those at $300 \mathrm{~K}$. Secondly, UFG $\mathrm{Al}$ at $77 \mathrm{~K}$ maintains high UTS and high tensile ductility even after the fatigue tests. These findings will be discussed later.

\subsection{Microstructural observation}

TEM images taken from fatigued and deformed specimens of $\mathrm{CG} \mathrm{Al}$ are shown in Figs. 4(a) to 4(c). After the fatigue tests of $\mathrm{CG} \mathrm{Al}$, fine dislocation walls were found to be developed in all grains (Fig. 4(a)). These dislocation walls were nearly parallel to $\langle 100\rangle$. It appears that two mutually perpendicular sets of walls exist in Fig. 4(c). These walls are considered to form layers, just like the labyrinth walls. ${ }^{32,35,37)}$ The average channel width between adjacent walls was about $350 \mathrm{~nm}\left(\varepsilon_{\mathrm{pl}}=1 \times 10^{-3}\right)$ and about $330 \mathrm{~nm}\left(\varepsilon_{\mathrm{pl}}=5 \times 10^{-3}\right)$. The absence of contrast variation among the channels indicates that the walls are made of edge dislocation dipoles. As will be discussed later, the observed channel widths in this study are much narrower than the frequently observed widths between 1 to $4 \mu \mathrm{m}$ in single-crystalline and $\mathrm{CG} \mathrm{Al}$ fatigued at room-temperature. ${ }^{32,37)}$

What should also be noted in Fig. 4 is that dislocation walls formed during fatigue in $\mathrm{CG} \mathrm{Al}$ persists even after monotonic tensile tests at 300 and $77 \mathrm{~K}$ and no distinct change in the dislocation wall structure was noted before and after the monotonic tensile tests (Figs. 4(b) and 4(c)).

Figures 5(a) to 5(d) show TEM images taken from fatigued and deformed specimens of UFG Al. Similar to $\mathrm{CG} \mathrm{Al}$, dislocation walls nearly parallel to $\langle 100\rangle$ are formed in many grains of UFG $\mathrm{Al}$ and the average channel width was about $320 \mathrm{~nm}\left(\varepsilon_{\mathrm{pl}}=1 \times 10^{-3}\right)$ and about $300 \mathrm{~nm}\left(\varepsilon_{\mathrm{pl}}=\right.$ $\left.5 \times 10^{-3}\right)$. From the observation such as that in Fig. 5(b), we find that the fraction of grains that contain dislocation wall structure is nearly $40 \%$. Considering the TEM visibility condition of dislocations, actual fraction may be larger. As is well known, dislocation multiplication and rearrangement are necessary to form certain fatigue dislocation structure
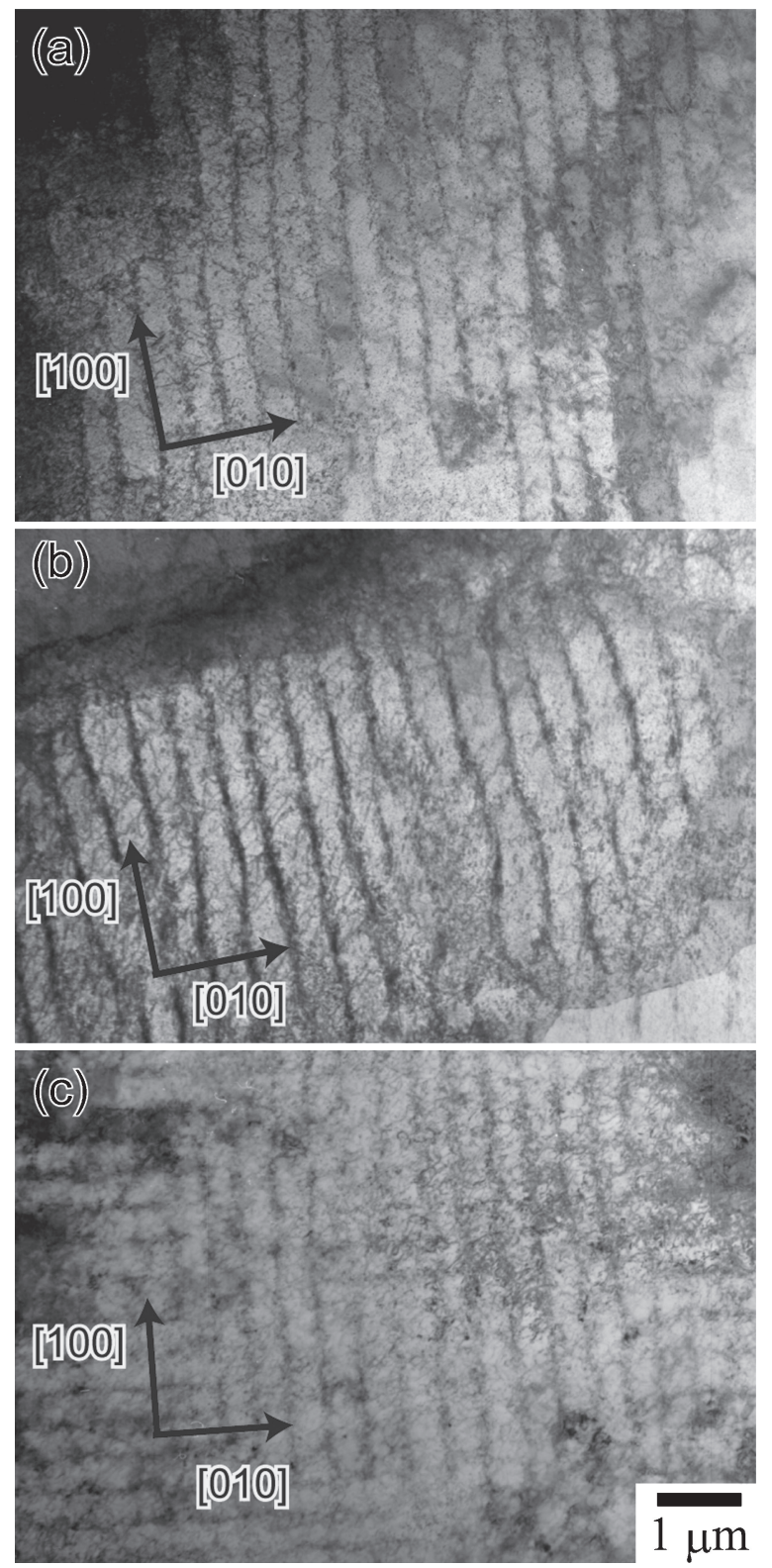

Fig. 4 TEM photographs of $\mathrm{CG} \mathrm{Al}$ : (a) fatigued at $77 \mathrm{~K}$ with $\varepsilon_{\mathrm{pl}}=$ $5 \times 10^{-3}$, (b) fatigued at $77 \mathrm{~K}$ with $\varepsilon_{\mathrm{pl}}=5 \times 10^{-3}$ and then monotonically deformed till failure at $300 \mathrm{~K}$, (c) fatigued at $77 \mathrm{~K}$ with $\varepsilon_{\mathrm{pl}}=5 \times 10^{-3}$ and then monotonically deformed till failure at $77 \mathrm{~K}$. Zone axis: [001].

including the present wall structure. If grain size is smaller, such dislocation activities would become more difficult due to smaller space and stronger constraint by the surrounding grain boundaries. Therefore, it is natural that the larger the grain size, the easier the formation of dislocation wall structure.

It is very interesting to find from Fig. 5 that dislocation wall structure formed during fatigue tests at $77 \mathrm{~K}$ disappears after succeeding monotonic tensile deformation (Figs. 5(c) and 5(d)). As described earlier, dislocation wall structure in CG Al persists even after monotonic tensile deformation at both test temperatures (Figs. 4(a) to 4(c)). Therefore, this disappearance of the wall structure is characteristic of UFG Al suggesting that the dislocation wall structure formed during fatigue tests in UFG Al is unstable against succeeding monotonic tensile deformation. 

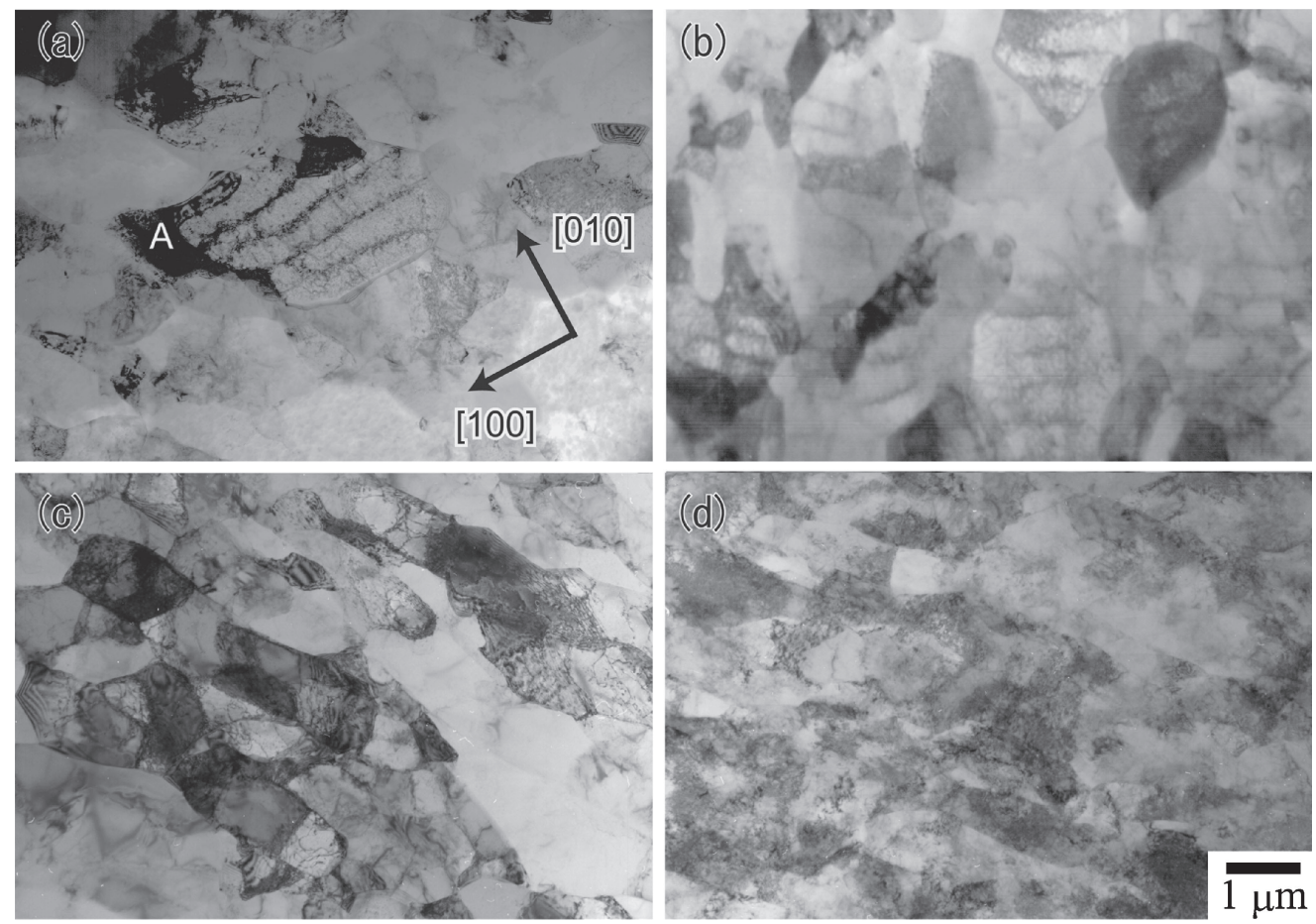

Fig. 5 TEM photographs of UFG Al: (a) fatigued at $77 \mathrm{~K}$ with $\varepsilon_{\mathrm{pl}}=5 \times 10^{-3}$, zone axis of grain A: [001], (b) fatigued at $77 \mathrm{~K}$ with $\varepsilon_{\mathrm{pl}}=5 \times 10^{-3}$. The fraction of grains that contain dislocation wall structure is about $40 \%$, (c) fatigued at $77 \mathrm{~K} \mathrm{with} \varepsilon_{\mathrm{pl}}=5 \times 10^{-3}$ and then monotonically deformed till failure at $300 \mathrm{~K}$, (d) fatigued at $77 \mathrm{~K}$ with $\varepsilon_{\mathrm{pl}}=5 \times 10^{-3}$ and then monotonically deformed till failure at $77 \mathrm{~K}$.

\section{Discussion}

\subsection{The relationship between the channel width and stress amplitude}

As mentioned earlier, the average channel width of $\mathrm{CG}$ and UFG Al fatigued at $77 \mathrm{~K}$ are much smaller than that of single-crystalline and $\mathrm{CG} \mathrm{Al}$ fatigued at $300 \mathrm{~K}^{32,37)}$ Basinski et $a l .{ }^{42}$ ) have reported that there is a linear relationship between shear stress amplitude $\tau_{\mathrm{a}}$ and the reciprocal of channel width $1 / d_{c}$, i.e.,

$$
\tau_{\mathrm{a}}=\frac{\alpha \mu b}{d_{\mathrm{c}}}
$$

where $\alpha$ is a dimensionless constant to be determined, $\mu$ the shear modulus and $b$ the magnitude of the Burgers vector. Though Brown ${ }^{43,44)}$ and Mughrabi and Pschenitzka ${ }^{45}$ proposed more detailed relationships, we adopt eq. (2) not only for simplicity but also for different geometry: the $\langle 100\rangle$ walls observed in the present study are different from the usual $\langle 110\rangle$ walls of the so-called ladder structure in fcc metals. ${ }^{46-49)}$

Converting the shear stress amplitude into uniaxial stress amplitude $\sigma_{\mathrm{a}}$ and using the Taylor factor $M=3.06$, eq. (2) becomes

$$
\sigma_{\mathrm{a}}=\frac{\alpha M \mu b}{d_{\mathrm{c}}} .
$$

With $\mu=26.7 \mathrm{GPa}$ and $b=0.286 \mathrm{~nm}$, calculated values of the constant $\alpha$ are shown in Table 1. According to theoretical studies by Brown ${ }^{43,50)}$ and Pedersen, ${ }^{51,52)}$ the value of $\alpha$ is estimated to be 2.0. Therefore, the calculated values of $\alpha$ listed in Table 1 are close to the theoretical value.
Table 1 Experimental values of stress amplitude $\sigma_{\mathrm{a}}$ and channel width $d_{\mathrm{c}}$ and calculated values of constant $\alpha$ for $\mathrm{CG} \mathrm{Al}$ and UFG Al.

\begin{tabular}{lccc}
\hline & $\begin{array}{c}\text { Stress } \\
\text { amplitude: } \\
\sigma_{\mathrm{a}}[\mathrm{MPa}]\end{array}$ & $\begin{array}{c}\text { Channel } \\
\text { width: } \\
d_{\mathrm{c}}[\mathrm{nm}]\end{array}$ & $\begin{array}{c}\text { Dimensionless } \\
\text { constant: } \\
\alpha\end{array}$ \\
\hline $\mathrm{CG}: \varepsilon_{\mathrm{pl}}=1 \times 10^{-3}$ & 118 & 350 & 1.7 \\
$\mathrm{CG}: \varepsilon_{\mathrm{pl}}=5 \times 10^{-3}$ & 126 & 330 & 1.8 \\
UFG: $\varepsilon_{\mathrm{pl}}=1 \times 10^{-3}$ & 151 & 320 & 2.0 \\
UFG: $\varepsilon_{\mathrm{pl}}=5 \times 10^{-3}$ & 186 & 300 & 2.4 \\
\hline
\end{tabular}

Figure 6 summarizes the experimental results of the inverse channel width under a given stress amplitude for single-crystalline $\mathrm{Al},{ }^{32,37,53)} \mathrm{UFG} \mathrm{Al},{ }^{39)} \mathrm{CG} \mathrm{Al}$ and UFG $\mathrm{Al}$ in this study. From the slope of the straight line, we find $\alpha=2.1$ which is again in good agreement with the theoretically-estimated value.

\subsection{Relationship between monotonic tensile deformation behavior and microstructural stability of CG and UFG Al}

The enhanced ductility of both $\mathrm{CG}$ and UFG $\mathrm{Al}$ at $77 \mathrm{~K}$ compared with that at $300 \mathrm{~K}$ (Figs. 2 and 3) has been known for many years. Some investigators have reported that both UTS and ductility of UFG Al become larger as temperature decreases. ${ }^{9,54,55)}$ The larger UTS is a natural result of strong temperature dependence of strength in UFG materials. ${ }^{25-27,56)}$ On the other hand, the larger ductility is mainly due to larger work hardening at $77 \mathrm{~K}$ than at $300 \mathrm{~K}$. Since larger work hardening increases the stability of plastic deformation and, thus, delays the formation of necking in 


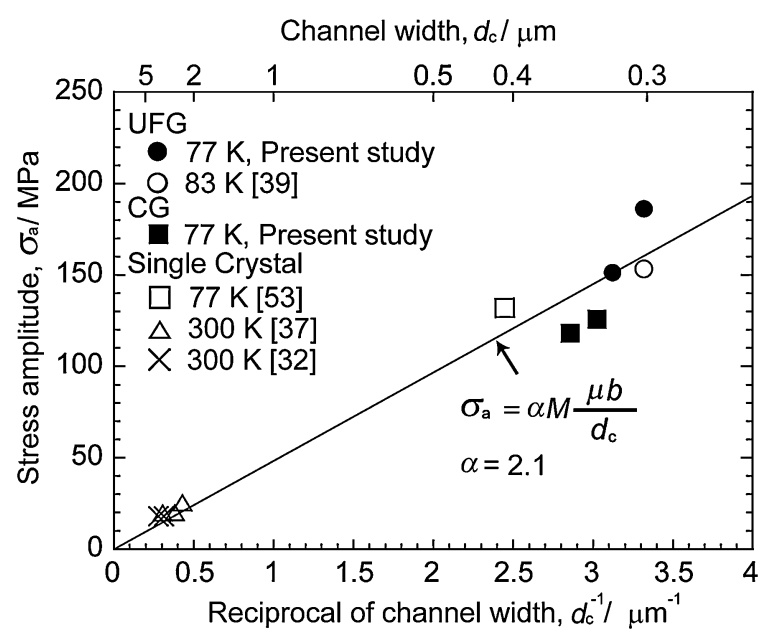

Fig. 6 Relationship between saturation stress amplitude $\sigma_{\mathrm{a}}$ and the reciprocal of channel width $d_{\mathrm{c}}$. Experimental data for Al single crystal, $\mathrm{CG} \mathrm{Al}$ and UFG Al are shown. Reference numbers are shown in the brackets. ${ }^{32,37,39,53)}$

tensile specimens, it can be understood that both strength and ductility increases at $77 \mathrm{~K}$ than at $300 \mathrm{~K}$ regardless of the grain size.

In this study, we found that the effect of fatigue tests on succeeding monotonic tensile deformation behavior is quite different between CG and UFG Al. Let us first discuss the experimental results for $\mathrm{CG} \mathrm{Al}$. The fact that fatigued CG Al showed much higher yield strength and lower ductility than as-annealed CG Al (Fig. 2) can be understood reasonably since $\mathrm{CG} \mathrm{Al}$ has experienced large cyclic hardening during the fatigue tests (Fig. 1). Dislocation wall structure is formed in all CG grains and it persists after monotonic tensile deformation (Figs. 4(b) and 4(c)). The persisting walls act as strong barriers against tensile deformation. Therefore, it is natural that fatigued $\mathrm{CG} \mathrm{Al}$ shows much higher yield strength and lower tensile ductility than as-annealed $\mathrm{CG} \mathrm{Al}$.

The characteristic finding for the UFG $\mathrm{Al}$ is, on the other hand, that dislocation wall structure formed in UFG $\mathrm{Al}$ disappears completely during monotonic tensile deformation at both test temperatures (Figs. 5(c) and 5(d)). As mentioned previously, since all the specimens were store in liquid nitrogen in this study, the disappearance of the dislocation wall structure after monotonic tensile deformation is not due to the natural recovery. That is, monotonic tensile tests certainly accelerate the disappearance of dislocation wall structure.

We should note that fatigued UFG Al shows nearly the same UTS and tensile ductility as as-ECAPed Al at both temperatures. Therefore, the observed high UTS and ductility in as-ECAPed and fatigued UFG Al are believed to have something to do with the disappearance of the dislocation structure. Figures 7(a) and 7(b) show the microstructure of UFG Al fatigued at $77 \mathrm{~K}$ with $\varepsilon_{\mathrm{pl}}=1 \times 10^{-3}$ and monotonically deformed at $77 \mathrm{~K}$ till a strain of 0.007 and 0.15 , respectively. In Fig. 7(a), broken traces of dislocation wall structure can be seen. However, at the strain of 0.15 (Fig. 7(b)), neither dislocation wall structure nor its traces can be seen any more. These results indicate that dislocation wall structure in UFG Al disappears in the early stages of succeeding monotonic tensile deformation and acts at most as weak barriers against dislocation motion during monotonic tensile deformation.

Why is the dislocation structure formed in UFG Al less stable than that in $\mathrm{CG} \mathrm{Al}$ ? It is known that store energy introduced in materials increases with increasing the number of ECAP passes. ${ }^{6,57)}$ For ECAPed $\mathrm{Cu}^{4,5)}$ and HPTed $\mathrm{Ni},{ }^{6}$ ) recovery and recrystallization are known to take place more easily at lower temperatures than conventional recrystallization temperature of near $0.5 T_{\mathrm{m}}\left(T_{\mathrm{m}}\right.$ : melting temperature). Recrystallization temperature decreases with increasing the stored energy. ${ }^{6}$ Moreover, Molodova et al. ${ }^{4)}$ reported that the apparent activation energy $Q_{\mathrm{R}}$ for recrystallization of ECAPed $\mathrm{Cu}$ decreases significantly with increasing the number of ECAP passes; $Q_{\mathrm{R}}$ decreases from $1 \mathrm{eV}$ at 1 pass to $0.7 \mathrm{eV}$ at 8 passes. These reports indicate that higher stored energy causes UFG materials energetically unstable and results in the larger driving force for recovery and recrystallization. We believe that such low thermal stability of UFG materials ${ }^{4-6,57)}$ explains, at least qualitatively, the easy disappearance of the dislocation wall structure.

Formation of dislocation wall structure is often related to the formation of persistent slip bands, surface intrusions and extrusions that are detrimental to fatigue resistance. ${ }^{48,58)}$ However, since grain size is very small and since the unstable dislocation wall structure is formed only in selected grains of UFG Al, the dislocation walls do not appear to cause the extensive formation of persistent slip bands. From this viewpoint, the present unstable dislocation walls formed
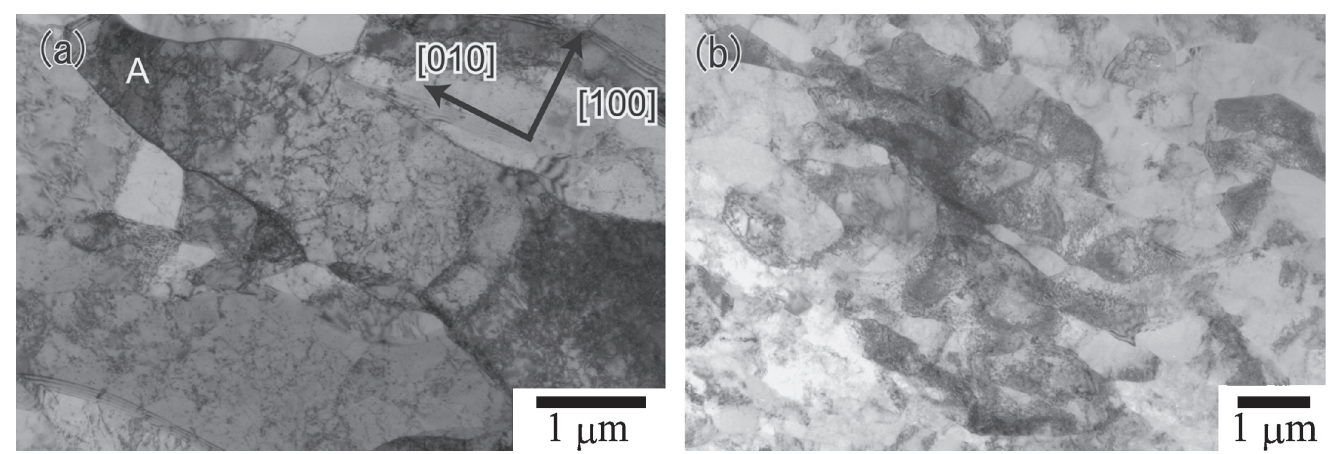

Fig. 7 TEM photographs of UFG Al fatigued at $77 \mathrm{~K}$ with $\varepsilon_{\mathrm{pl}}=1 \times 10^{-3}$ and then deformed in tension at $77 \mathrm{~K}$, (a) monotonic tensile test stopped at $\varepsilon=0.007$, zone axis of grain A: [001], (b) monotonic tensile test stopped at $\varepsilon=0.15$. 
in UFG $\mathrm{Al}$ at $77 \mathrm{~K}$ may not be so harmful to the fatigue resistance. This is most probably the reason why ECAPed and fatigued UFG Al maintains nearly the same tensile strength and ductility as as-ECAPed UFG Al. Further studies are needed to discuss in more detail the relationship between the fatigue resistance and the degree of microstructural stability of UFG materials.

\section{Conclusions}

The low-cycle fatigue tests of high purity CG and UFG Al (99.98\%) were carried out at $77 \mathrm{~K}$. After the fatigue tests, $\mathrm{CG}$ and UFG Al were deformed in tension at 300 and $77 \mathrm{~K}$. The results and findings are summarized as follows.

(1) During the strain-controlled fatigue tests, both CG and UFG Al show hardening to stress saturation at $77 \mathrm{~K}$. The cyclic hardening rate of UFG $\mathrm{Al}$ is lower compare to that of $\mathrm{CG} \mathrm{Al}$.

(2) Fatigued CG Al shows much higher tensile strength and lower tensile ductility than as-annealed $\mathrm{CG} \mathrm{Al}$ at 300 and $77 \mathrm{~K}$. On the other hand, fatigued UFG $\mathrm{Al}$ shows almost the same tensile strength and ductility as as-ECAPed UFG $\mathrm{Al}$ at both 300 and $77 \mathrm{~K}$.

(3) Fine dislocation wall structure is formed in all the $\mathrm{CG}$ grains during fatigue at $77 \mathrm{~K}$. This dislocation wall structure in $\mathrm{CG} \mathrm{Al}$ persists after monotonic tensile deformation at both 300 and $77 \mathrm{~K}$.

(4) Very fine dislocation wall structure is formed in UFG Al during fatigue tests at $77 \mathrm{~K}$ and the fraction of the grains that contain the dislocation wall structure is about $40 \%$. The dislocation wall structure in UFG $\mathrm{Al}$ is found to disappear easily during the early stages of monotonic tensile deformation.

(5) Good correlation is found between the reciprocal of the channel width and the saturation stress amplitude, from single-crystalline Al to UFG Al.

(6) Relatively unstable dislocation wall structure in UFG $\mathrm{Al}$ acts as a weak barrier for dislocation motion in monotonic tensile tests and may not be harmful in reducing the fatigue resistance.

\section{Acknowledgments}

This study was supported by a Grant-in-Aid for Scientific Research on Innovative Area, "Bulk Nanostructured Metals" through MEXT, Japan (contract No. 22102006).

\section{REFERENCES}

1) Y. Iwahashi, Z. Horita, M. Nemoto and T. G. Langdon: Acta Mater. 46 (1998) 3317-3331.

2) Y. Saito, N. Tsuji, H. Utsunomiya and S. Tanigawa: Scr. Mater. 39 (1998) 1221-1227.

3) Z. Horita and T. G. Langdon: Mater. Sci. Eng. A 410-411 (2005) 422 425.

4) X. Molodova, G. Gottstein, M. Winning and R. J. Hellmig: Mater. Sci. Eng. A 460-461 (2007) 204-213.

5) Y. Zhang, J. T. Wang, C. Cheng and J. Liu: J. Mater. Sci. 43 (2008) 7326-7330.

6) H. W. Zhang, X. Huang, R. Pippan and N. Hansen: Acta Mater. 58 (2010) 1698-1707.
7) Q. Wei, S. Cheng, K. T. Ramesh and E. Ma: Mater. Sci. Eng. A 381 (2004) 71-79.

8) T. Kunimine, N. Takata, N. Tsuji, T. Fujii, M. Kato and S. Onaka: Mater. Trans. 50 (2009) 64-69.

9) C. Y. Yu, P. W. Kao and C. P. Chang: Acta Mater. 53 (2005) 40194028.

10) N. Kamikawa, X. Huang, N. Tsuji and N. Hansen: Acta Mater. 57 (2009) 4198-4208.

11) R. O. Scattergood and C. C. Koch: Scr. Metall. Mater. 27 (1992) 11951200 .

12) J. Lian, B. Baudelet and A. A. Nazarov: Mater. Sci. Eng. A 172 (1993) 23-29.

13) R. A. Masumura, P. M. Hazzledine and C. S. Pande: Acta Mater. 46 (1998) 4527-4534.

14) D. Jia, Y. M. Wang, K. T. Ramesh, E. Ma, Y. T. Zhu and R. Z. Valiev: Appl. Phys. Lett. 79 (2001) 611-613.

15) H. Van Swygenhoven, H. Caro and D. Farkas: Mater. Sci. Eng. A 309310 (2001) 440-444.

16) E. Nes and K. Mathinsen: Mater. Sci. Eng. A 322 (2002) 176193.

17) Y. M. Wang, E. Ma and M. W. Chen: Appl. Phys. Lett. 80 (2002) 2395-2397.

18) S. Cheng, J. A. Spencer and W. W. Milligan: Acta Mater. 51 (2003) 4505-4518.

19) A. Hasnaoui, P. M. Derlet and H. Van Swygenhoven: Acta Mater. 52 (2004) 2251-2258

20) H. S. Kim and Y. Estrin: Acta Mater. 53 (2005) 765-772.

21) R. J. Asaro and S. Suresh: Acta Mater. 53 (2005) 3369-3382.

22) G. Saada: Philos. Mag. 85 (2005) 3003-3018.

23) M. A. Meyers, A. Mishra and D. J. Benson: Prog. Mater. Sci. 51 (2006) 427-556.

24) R. W. Armstrong and P. Rodriguez: Philos. Mag. 86 (2006) 57875796.

25) Y. M. Wang, A. V. Hamza and E. Ma: Acta Mater. 54 (2006) 27152726.

26) M. Kato, T. Fujii and S. Onaka: Mater. Trans. 49 (2008) 1278-1283.

27) M. Kato: Mater. Sci. Eng. A 516 (2009) 276-282.

28) M. K. Wong, W. P. Kao, J. T. Lui, C. P. Chang and P. W. Kao: Acta Mater. 55 (2007) 715-725.

29) J. May, D. Amberger, M. Dinkel, H. W. Höppel and M. Göken: Mater. Sci. Eng. A 483-484 (2008) 481-484.

30) S. Malekjani, P. D. Hodgson, P. Cizek, I. Sabirov and T. B. Hilditch: Int. J. Fatigue 33 (2011) 700-709.

31) M. Soliman, E. A. El-Danaf and A. A. Almajid: Mater. Sci. Eng. A 532 (2012) 120-129.

32) M. Videm and N. Ryum: Mater. Sci. Eng. A 219 (1996) 1-10.

33) M. Videm and N. Ryum: Mater. Sci. Eng. A 219 (1996) 11-20.

34) T. Fujii, N. Sawatari, S. Susumu and M. Kato: Mater. Sci. Eng. A 387-389 (2004) 486-490.

35) P. Charsley and L. J. Harris: Scr. Metall. 21 (1987) 341-344.

36) P. Charsley, U. Bangert and L. J. Appleby: Mater. Sci. Eng. A 113 (1989) 231-236

37) T. Fujii, S. Uju, H. Tanaka, T. Murayama, C. Watanabe, S. Onaka and M. Kato: Plasticity, Failure and Fatigue in Structural Materials from Macro to Nano, Proceedings of the Hael Mughrabi Honorary Symposium, ed. by K. J. Hsia, M. Göken, T. Pollock, P. D. Portella and N. R. Moody, (The Minerals, Metals \& Material Society, 2008) pp. 123-127.

38) Y. Nakanishi, T. Fujii, S. Onaka and M. Kato: Proc. 12th Int. Conf. on Aluminium Alloys, ed. by S. Kumai, O. Umezawa, Y. Takayama, T. Tsuchida and T. Sato, (The Japan Inst. Light Metals, 2010) pp. 326331.

39) Y. Nakanishi, T. Fujii, S. Onaka and M. Kato: Mater. Trans. 52 (2011) 890-894.

40) A. A. Salem, T. C. Langdon, T. R. Mcnelley, S. R. Kalidindi and S. L. Semiatin: Metall. Mater. Trans. A 37 (2006) 2879-2891.

41) M. Kawasaki, Z. Horita and T. G. Langdon: Mater. Sci. Eng. A 524 (2009) 143-150.

42) Z. S. Basinski, A. S. Korbel and S. J. Basinski: Acta Metall. 28 (1980) 191-207.

43) L. M. Brown: Mater. Sci. Eng. A 285 (2000) 35-42. 
44) L. M. Brown: Philos. Mag. 86 (2006) 4055-4068.

45) H. Mughrabi and F. Pschenitzka: Philos. Mag. 85 (2005) 3029-3045.

46) P. Lukáš, M. Klesnil and J. Krejčf: Phys. Status Solidi (b) 27 (1968) 545-558.

47) C. Laird: Mater. Sci. Eng. 81 (1986) 433-450.

48) P. Lukáš and L. Kunz: Philos. Mag. 84 (2004) 317-330.

49) P. Li, S. X. Li, Z. G. Wang and Z. F. Zhang: Acta Mater. 58 (2010) 3281-3294.

50) L. M. Brown: Metall. Trans. A 22 (1991) 1693-1708.

51) O. B. Pedersen: Acta. Metall. 38 (1990) 1221-1239.

52) O. B. Pedersen: Philos. Mag. 73 (1996) 829-858.
53) T. Fujii: Proc. 12th Int. Conf. on Aluminium Alloys, ed. by S. Kumai, O. Umezawa, Y. Takayama, T. Tsuchida and T. Sato, (The Japan Inst. Light Metals, 2010) pp. 322-325.

54) P. L. Sun, E. K. Cerreta, J. F. Bingert, G. T. Gray, III and M. F. Hundley: Mater. Sci. Eng. A 464 (2007) 343-350.

55) Y. Z. Estrin: Low Temp. Phys. 34 (2008) 665-671.

56) G. A. Malygin: Phys. Solid State 49 (2007) 1013-1033.

57) W. Q. Cao, C. F. Gu, E. V. Pereloma and C. H. J. Davies: Mater. Sci. Eng. A 492 (2008) 74-79.

58) N. Thompson, N. J. Wadsworth and N. Louat: Philos. Mag. 1 (1956) $113-126$. 